\title{
Psychiatric Assessment and Interventions in Radicalised Individuals: A Delphi Study of the 'Lone-Wolf' Terrorism
}

\author{
Carlo Lazzari $^{1}$, Georgios Mousailidis ${ }^{2}$, Abdul Nusair ${ }^{1}$, Basavaraja Papanna ${ }^{2 *}$ and Ahmed Shoka ${ }^{2}$ \\ ${ }^{1}$ South-West Yorkshire NHS Foundation Trust, Field head Hospital, Wakefield \\ ${ }^{2}$ Essex Partnership University NHS Foundation Trust, Kingwood Centre, Colchester \\ *Corresponding Author: Basavaraja Papanna, Essex Partnership University NHS Foundation Trust, Kingwood Centre, Colchester.
}

Received: October 30, 2019; Published: November 13, 2019

DOI: 10.31080/ASNE.2019.02.0126

\begin{abstract}
The world has been the scene of many alarming scenarios of terrorist attacks from radicalised people who act individually without formal membership to any terrorist group. They are called 'lone wolves' or 'lone actors.' Mental-health professionals can help identify and prevent radicalisation by robust assessment of people at risk of radicalisation. Also, community mental-health practitioners are in the privileged position to detect social signs that are indicative of a radicalised entourage which might favour potential victims of it, including children. The current Delphi study, conducted by psychiatrists familiar with radicalisation in different countries and across varied cultures and explains major aspects of the psychiatry of radicalisation in the lone-wolf.
\end{abstract}

Keywords: Interventions in Radicalised; Lone-Wolf

\section{Introduction}

Radicalisation is defined as "The action or process of causing someone to adopt radical positions on political or social issues" [1]. Similarly, 'radical' derives from the Latin 'radix or root [2]. Radicalisation has diverse components consisting of the person who is radicalised, the person who is radicalising, and the outcome action resulting in a terrorist attack. One could perhaps describe this process as the "Radicalisation Triangle". Radicalisation has also been defined as a behaviour by which individuals embrace a political, social or religious ideology that leads to terrorist acts [3]. Prevent ${ }^{\circledR}$ defines radicalisation as the practice leading people to endorse terrorism or radical ideologies leading to terrorism [4]. Brutal radicalism exacerbates feelings of uncertainty, which can lead to recurrent conflicts; these last will then jeopardize economic development hence triggering a vicious circle of radicalisation $\leftrightarrow$ economic instability [5]. In recent years, more devastating terrorist attacks have been conducted by lone-wolves who were living in the country, region or town where the attacks occurred.
Internal terrorism occurs when offenders, victims, locations, witnesses are all in the same nation [6].

As occurring in the world of true wolves, the subjects who become lone wolves have somewhat experienced that they do not fit into their crowd; they have probably been bullied, considered as inadequate and ignored by their group [7]. Therefore, a terrorist attack by a lone wolf is completed by a solitary subject hence removing couples and small groups [7].

The lone wolf can take the life of many innocent peoples as he or she is just 'one between us.' It is the case of the recent gunman in New Zealand who took the life of 50 people, including children, gathered in a mosque in Christchurch [8]. A 'lone-wolf' or 'lone-actor' is usually identified as a person who conducts a terrorist attack alone and is mostly self-radicalised. Hence, a lone-wolf has self-radicalised mind set, has no contacts with other extremist groups, plans a terrorist attack with no inspiration from other persons or 
organizations, and has no support for planning and executing the violent act [9]. Furthermore, a lone wolf has no direct leader while terroristic strategies and means are invented and managed directly by the lone wolf without any external order or control [10].

\section{Psychiatry of radicalisation}

A Delphi group was created within psychiatrists who have experience in the subject of radicalisation and terrorist and who had direct or indirect contact with radicalised individuals at some point during their career. Several authors define a Delphi group as a research method which has planned group communications and critical forecasting, end eavouring at analytically sharing ideas focusing on an arena of common concern, among a group of designated specialists in the themes of discussion and acquiring a shared understanding that decreases ambiguity and improves choices [11].

Our Delphi group was encouraged in discussion with four major questions posed during consensus meetings: What are the major psychiatric aspects of radicalisation and terrorism in the lone wolf? How does radicalisation start in the lone wolf and others? What are the mind frames of radicalised individuals? How to de-radicalise? The Delphi group designed for the current study consisted of a panel of 3 psychiatric consultants and 2 specialist registrars with special interest in themes of radicalisation. During the period from 2017 to 2019, the panel met once a month during face-to-face encounters or online conferences to discuss cogent themes linked to lone-wolf radicalisation and terrorism. A group conductor (lead author) stimulated the discussions on agreed themes and questions. Comments were collected as narratives and elaborated for consensus on leading topics about radicalisation and terrorism and for a possible construction of an assessment tool in the future [12]. Delphi groups have been created in several countries to make evaluations and predictions of radicalised terrorism [13]. It is reported that Delphi groups of highly motivated participants can reach an accuracy of about $75 \%$ in predicting the occurrence of terroristic attacks [14].

In a paper published by the Royal College of Psychiatrists it is stated that 'Radicalisation is not a mental illness' explaining that it is rather 'a change in the mindset and behaviour of an individual that leads to an alteration in worldview, perception of external events and his or her understanding of them'[15]. However, it is suggested that when radicalisation progresses to a terrorist attack, then a discourse of psychiatric pathology starts to be more grounded. Recent investigations by UK Police of persons convicted of radicalisation from 1998 to 2015, found that fifteen cases of persons suffered from mental illnesses; they were already known as previously detained under sections of the Mental Health Act 1983 or treated in a secure psychiatric ward [16]. Another study found that depression is connected to a proclivity to become radicalised with traits like lack of identity, social isolation, anger where ambiguity being a trigger; while mental illnesses, in general, are more likely in the lone wolf than group terrorists [17]. The aim of psychiatrists is to reduce any risk to others that derive form behaviours that are socially condemned. At the same time, psychiatrists are interested in deviations from the norm of ways of thinking, feeling and behaving.

The relationship between mental health and radicalisation remains debatable although deviance, violence, lack of empathy, a risk to others, antisocial behaviours, psychoses and substance misuse might ignite a vulnerable mind to become radicalised and commit a terrorist act [18]. In an Australian study of radicalised persons, it was found that people who have been convicted of radicalisation not always had a history of antisocial behaviours [19]. Instead, those who were more antisocial were also more inclined to detach from societal morals while for the majority, the trigger to radicalisation was the search of a goal in life, and need to boost self-esteem and recognition [19]. On the other hand, opposition to crime has also been found linked to job consistency, positive marital relations and successful military involvements [20]. Persons with personal antisocial disorder and inclination to violence are more likely to embrace radical viewpoints and are more competent for armed fighting than those who are depressed [20].

Those with pre-existing antisocial and pro-violent dispositions may be more likely to hold extreme attitudes and be more suited for military action [21]. In this respect, the tradition of Western psychiatry can help understand radicalisation as this approach holds an individualistic approach focusing explanation, assessment and intervention on the adult or children who are radicalised [22].The first spontaneous link then goes to pathologies of mind and behaviour, and specifically to some psychopathy. Inadequate parenting is conducive since childhood to the seeds of antisocial behavior, which, in case of radicalisation, mainly manifests as dis- 
regard of the emotions of other people and the way they feel about the ramifications of the conduct of a sociopath [23].

However, studies trying to establish the presence of psychopathological features in radicalised persons are inconsistent. In a French study of radicalised youths, it was found that suicidal proclivity as adolescences might find martyrdom appealing because it brings sense to a fragile existence and suicidality [24]. At the same time, according to our Delphi group, radicalisation presents with core emotional drives, including a basic feeling of vulnerability, and feeling victimized; both emotions are conducive to the need of having more power and recognition, while feeling blocked in reaching these goals via popular or legal routes [25].

Family upbringing can be radicalising either due to exposing children to violent indoctrination or by inculcating in them the unconscious messages of life-long preparation to 'win historic injustices [26].The constant variable that animates radicalised persons or families is a bias or prejudice towards targeted victims of a terrorist attack or the 'diverse' others. According to Collins Dictionary Online, 'Prejudice is an unreasonable dislike of a particular group of people or things or a preference for one group of people or things over another [27]. At the same time, the Merriam-Webster dictionary defines 'Terror as violent or destructive acts (such as bombing) committed by groups to intimidate a population or government into granting their demands [28].

There is an element of narcissism associated with sociopathy, which makes radicalised ideas, groups or nations attractive to some people who aim to embrace and emulate strong models to suffice weak personalities. The fashion of young ladies who travel to Syria to become ISIS brides is a recent example. These are trusting and vulnerable personalities, which then become themselves victims of torture and rape [29]. Children as well can be at risk of radicalisation and nursery schools have been alerted to look for signs of radicalisation. The Guardian reports a recent case where a boy drew a 'cooker bomb' he saw being manufactured in his house by his father [30]. In a study conducted by the United Nations in Jordan, $82 \%$ of people interviewed reported that families and mother's approaches have a great impact on radicalising children [31]. Our Delphi group commented that some form of positive or negative indoctrinations exists within each family upbringing. In its advanced forms, abusive or radicalising families tend to radica- lise their children to make them more prone to accept uncritically certain ideas and to have them perform socially disapproved behaviours with little remorse. As a child is always in a dependent relationship with his or her parents, he or she accepts radicalisation as a matter of personal adaptation to the family milieu. In a study including 22 qualitative and quantitative studies, it emerged that young radicalised Europeans were victims of three major risk factors inclusive of early-life abuses, dysfunctional families, radicalising friends, political and economic challenges inclusive of Durkheim's anomie [32]. The concept of 'Anomie' introduced by Durkheim, meaning 'in societies or individuals, a condition of instability resulting from a breakdown of standards and values or from a lack of purpose or ideals [33]. Several studies have shown a direct effect of anomic conditions and homicide [34]. A high grade of anomie suggests that social behaviours are no longer regulated by the prevailing moral norms and authority [35]. Socioeconomic factors are also triggers as it is hypothesized that high income disparity and chronic unemployment trigger anomic crimes [36]. Anomie equals normless and although social norms are usually accompanied by antisocial behaviours, the internalisation of norms and regulations (hence, a low degree of anomie) is a delicate balance between the individual's intelligence to cope with social norms and his or her harmful behaviours triggered by a pathological personality disorder [37].

As moral development occurs within and because family upbringing, we hypothesize that radicalised children and youths are in Kohlberg's stage of pre-conventional morality, which can also stretch to adulthood in anomic conditions. At this stage, a young person at the pre-conventional stage has no moral code; instead, actions are molded by copying the available ethics of primary role models, and obedience is achieved to avoid the punishment which is a signal of 'wrong-doing [38]. Radicalised individuals might function at a preconventional stage as they are likely to respond to normative principles not because sharing the same moral principles of the majority but because tend to avoid 'hustles with the law'. Moreover, radicalisation can exist as long there is a victim considered as allegedly guilty for the extremist's conditions. This cognitive reframing will then reduce internal moral conflicts. Hence, violence and terrorist attacks are directed to others considered by the lone wolves as the perpetrators of their tribulation [39]. Despite the attempt to find some sign of mental 'weakness' or pathological cognitive frames in radicalised persons, studies will dismay 
this attempt as there are also radicalised physicians [40]. Most of the times, the lone wolf avoids the moral conflict from social disapproval via a cognitive reframing of the self and others. In this case, social condemnation paradoxical reinforces the idea of personal uniqueness, entitlement and martyrdom in the radicalised person. The origin of radical thoughts gets quick catch into simple minds. An innovative idea, able to clarify a multifaceted event directly and understandably, gains in popularity while triggering a chain reaction in the social media; anyone then adopts it because it seems conceivable [41]. Although it might be antisocial. Regarding the predictability of the radical violence an American research of 119 people convicted for terrorist attacks or ideation, and identified as lone-actors, found that $39 \%$ suffered from mental illness, in $79 \%$ of cases others were aware of their radicalised ideas, while in $59 \%$ of cases the offenders made aware the media about their intentions prior to the terrorist attack [42]. In the attempt to identify possible personality traits in the lone-wolf, our Delphi group suggested that the typologies of the Dark Triad could be the most common personality trait of the lone wolf. The Dark Triad comprises three personality traits that have been linked to inconsiderate actions: Machiavellianism, as an attempt to negatively influence others, Narcissism, as a feeling of ostentation or dominance, and Psychopathy, characterised by impulsivity and lack of empathy for others [43]. A study found a correlation of physical and verbal sadism with the dark triad and especially with psychopathy; for sadists, the aim to damaging others is found as gratifying [44]. There seems to be a correlation between impulsivity and the psychopathy trait of the dark triad [45]. However, as the terrorist attack requires long-term planning, Machiavellianism could be inferred. One study indicates that those high with Machiavellianism traits more prominent than psychopathy in the dark triad also have more intact executive functioning hence being able to long-term planning and control of the self [46]. These last qualities are needed to plan successful terrorist attacks. From our Delphi group, there was a consensus that radicalisation can start very early as the trends of radicalising children to become terrorist militias are popular in radicalised countries or groups. It is estimated that up to 500,000 children are involved in armed conflicts around the world [47]. As monitored by the Child Soldiers International there has been an increase of $159 \%$ in recruiting children to be involved in conflict areas with a verified number of 30,000 cases of children recruited [48]. Hence, there is a potential risk that the process of radicalisation starting early, like in the case children soldiers, can increasingly bring to radicalisation and terrorist attack persons of younger age as adolescents also in Western countries. Children can be abducted to radicalisation and armed conflicts after they witnessed violence to their families or have lost family members in conflict areas; other times they are forcibly abducted to commit massacres like in Liberia, Sierra Leone and Uganda [49]. In other cases, youths who are victims of extreme poverty and marginality are easily abducted by deceitful appeals of accessing better economic conditions by ideologies levering on their feelings of injustice like in Colombia, Nepal and India's Maoist states [49]. The same occurred during the years of the 60 s in Italy with the radicalised left-wing terrorist group Red Brigades that were able to abduct people and to attract consensus in many by just levering on their feelings of economic injustice, anger, revenge and 'radical changes.' In 1970, Red Brigades comprised 500 full-time members, 1,000 periodical members and thousands of fans [50].

\section{De-radicalisation}

Collins Dictionary Online defines 'Deradicalisation as the practice of encouraging those with extreme and violent religious or political ideologies to adopt more moderate views' [51]. Deradicalisation is also defined as the method of changing a person's creeds, helping him or her declining radical ideas, and assisting in accepting the principles of the majority [52].

A successful plan for deradicalisation entails the close partnership among different private and public organisations while ensuring that frontline professionals are not targeted by extremists during their attempt to deradicalise lone wolves [53]. A holistic method of deradicalisation has been proposed as consisting of three stages: 1) training to embrace new and moderate beliefs; 2) professional training or economic assistance; 3 ) proper settings for rehabilitation [54]. One crucial scenario where to focus the attention is in programs to deradicalise prisoners. One suggestion is to separate violent extremists for other inmates to avoid proselytism and the risk of radicalisation of prisoners who are not radicalised yet [55].

Our Delphi group suggests that de-radicalisation should address those psychiatric aspects that can increase feelings of resentment, retaliation and anger towards others and society. There are vast areas in all countries where people feel betrayed by their government and political representatives. People who feel emarginated, betrayed or ignored by the mainstream institutions might harbour feelings of rancor towards the prevailing ideologies and the main- 
stream population. The idea that only radical changes can make a difference can grow exponentially in the lone wolf. The consequence is an ideological trap and the decision to embrace more violent and extremist ideologies and solutions to make a difference in the lone-wolf's life and to achieve status and identity. If assessment instruments help in identifying the seeds of radical ideas [18] then mental-health professionals can play a pivotal role in systematic de-radicalisation of the population at risk.

Children and youngsters are other sensitive targets for interventions. They are vulnerable to embrace dualistic thoughts and being driven to think radical only by emulation of deviant adults or by approaching ideological traps on the internet. As proposed by Prevent, schools should offer a protected environment where children, teenagers, and adult can explore the perils associated with radical ideologies and radicalism while maturing information and competences to counteract extremist ideologies [56].

Our Dephi group has proposed that in order to de-radicalise, psychiatric professionals should pay particular attention to Negative Emotions addressed to specific Objects of Resentment (OR) like local or foreign governments or countries, local institutions, and other ethnic or religious groups which are believed, by the lone wolves, to be the culprit for their own conditions, hence increasing anomic feelings, inclination to violence and radicalisation: 1 ) anger expressed a chronic feeling of inflicted wrongdoing by part of OR; 2) frustration and feeling helpless and hopeless in changing their social conditions; 3 ) demanding 'proper' recognition by OR; 4) failing in achieving specific goals in their own life because of OR; 5) has a positive forensic history for violence or attacks to total institutions and OR; 6) describes self as socially isolated and aloof and attributing the reason to conflicts with OR; 6) feeling betrayed by mainstream institutions, the own organisation and other OR; 7) might have a history of admission into psychiatric hospitals or forensic units with paranoid psychosis or delusional beliefs centered on OR. Other studies have shown the implication of anger and frustration on lethal violence [34].

\section{Conclusions}

The current Delphi study has highlighted the significant psychiatric aspects of radicalisation and terrorism. Consequently, the present study fills the gap still existing in the placement of radicalisation into a perspective which is not only political, social and psychological, but also psychiatric, behavioural and developmen- tal. A psychiatric viewpoint is also inclusive of risk assessment and prevention, hence allowing the suggestion of what could be considered individual elements indicative of existing radicalisation or a proclivity to extremism and terrorism. A constellation of behaviours, feelings and beliefs make radicalisation a possible candidate for psychiatric nosology and diagnosis. Similarly, the strategic presence of mental-health professionals in the community and hospitals is likely to spot social signs of a radicalising milieu and the potential presence of lone wolves. Further research in this direction might help in preventing radicalisation or terrorism with the support of robust psychiatric theories, assessment and interventions.

\section{Bibliography}

1. Oxford Dictionary Online. Radicalization | Definition of radicalization in English by Oxford Dictionaries [Internet]. Oxford Dictionaries | English (2019).

2. Online Ethymology Dictionary. Radical | Origin and meaning of radical by Online Etymology Dictionary [Internet]. Etymonline.com. (2019).

3. Misiak B., et al. "A systematic review on the relationship between mental health, radicalization and mass violence". European Psychiatry 56 (2019): 51-59.

4. Secretary of State for the Home Department. Prevent Strategy Norwich: TSO (The Stationery Office) (2019).

5. United Nations. Plan of Action to Prevent Violent Extremism (2015).

6. Sandler T. "New frontiers of terrorism research: An introduction". Journal of Peace Research 48.3 (2011): 279-286.

7. Danzell OE and Maisonet Montañez LM. "Understanding the lone wolf terror phenomena: assessing current profiles". Behavioral Sciences of Terrorism and Political Aggression 8.2 (2016):135-159.

8. Shadwell T., et al. All 50 worshippers killed in New Zealand mosque terror attacks named (2019).

9. Borum R., et al. "A dimensional approach to analyzing lone offender terrorism". Aggression and Violent Behavior 17.5 (2012): 389-396.

10. Hamm M and Spaaj R. "Lone wolf terrorism in america: Using knowledge of radicalization pathways to forge prevention strategies". Indiana State University (2015). 
11. Winkler J and Moser R. "Biases in future-oriented Delphi studies: A cognitive perspective". Technological Forecasting and Social Change 105 (2016): 63-76.

12. Lazzari C and Shoka A. Radicalization Assessment Psychiatric Test_RAPT_001 Survey (2017).

13. Van de Linde E and van der Duin P. "The Delphi method as an early warning: Linking global societal trends to future radicalization and terrorism in The Netherlands". Technological Forecasting and Social Change 78.9 (2011): 1557-1564.

14. Parenté R., et al. "The Delphi method, impeachment and terrorism: Accuracies of short-range forecasts for volatile world events". Technological Forecasting and Social Change 72.4 (2005): 401-411.

15. Royal College of Psychiatrists. Counter-terrorism and psychiatry (2016): 4

16. Malik N. Mental health and terrorism: What are the links? Forbes (2019).

17. Misiak B., et al. "A systematic review on the relationship between mental health, radicalization and mass violence". European Psychiatry 56 (2019): 51-59.

18. Dom G., et al. "Mass violence, radicalization and terrorism: A role for a psychiatric profession?". European Psychiatry 49 (2018): 78-80.

19. Porter L and Kebbell M. "Radicalization in Australia: Examining Australia's convicted terrorists". Psychiatry, Psychology and Law 18.2 (2011): 212-231.

20. Laub J and Sampson R. "Understanding desistance from crime". Crime Justice 28 (2001): 1-69.

21. Coid J., et al. "Extremism, religion and psychiatric morbidity in a population-based sample of young men". British Journal of Psychiatry 209.6 (2016): 491-497.

22. Knudsen RA. "Measuring radicalisation: risk assessment conceptualisations and practice in England and Wales". Behavioral Sciences of Terrorism and Political Aggression (2018).

23. Oyebode F. "Sim's Symptoms in the Mind". (5th ed.). London, etc.: Saunders (2015).

24. Campelo N., et al. "Who are the European youths willing to engage in radicalisation? A multidisciplinary review of their psychological and social profiles". European Psychiatry 52 (2018): 1-14.
25. Lazzari $\mathrm{C}$ and Rabottini M. "Psychiatry of radicalization and terrorism". European Psychiatry 56S (2019): EPP0560.

26. Lazzari C and Rabottini M. "Psychiatry of radicalizing family". European Psychiatry 56S (2019): EPV0370.

27. Collins Dictionary Online. Prejudice definition and meaning | Collins English Dictionary (2019).

28. Merriam-Webster Dictionary. Definition of Terror (2019).

29. Corcoran L and Carr S. "The accounts of three former ISIS brides are heartbreaking (2019).

30. Quinn B. Nursery 'Raised fears of radicalisation over boy's cucumber drawing' (2019).

31. United Nations Women, The Jordan National Commission for Women. Women and Violent Radicalization in Jordan (2019).

32. 'Researchers' Work from Institute for Psychology Focuses on Psychiatry (Who are the European youths willing to engage in radicalisation? A multidisciplinary review of their psychological and social profiles)." Mental Health Weekly Digest (2018):103.

33. Encyclopedia Britannica Online. Definition of 'Anomie' (2019).

34. Stults BJ and Baumer EP. "Assessing the relevance of anomie theory for explaining spatial variation in lethal criminal violence: An aggregate-level analysis of homicide within the United States". International Journal of Conflict and Violence 2.2 (2008): 215-247.

35. Messner SF., et al. "Institutions, anomie, and violent crime: Clarifying and elaborating institutional-anomie theory". International Journal of Conflict and Violence 2.2 (2008):163-181.

36. Frerichs S., et al. "Anomic crime in post-welfarist societies: Cult of the individual, integration patterns and delinquency". International Journal of Conflict and Violence 2.2 (2008): 194-214.

37. Rose G. "Anomie and deviation: A conceptual framework for empirical studies". The British Journal of Sociology 17.1 (1966): $29-45$.

38. McLeod S A. Kohlberg (2013).

39. Doosje B., et al. "Terrorism, radicalization and de-radicalization". Current Opinion in Psychology 11 (2016): 79-84. 
40. DeMaria A. "Radicalized physicians". Journal of the American College of Cardiology 55.7 (2010): 698-699.

41. Leistedt S. "On the radicalization process". Journal of Forensic Sciences 61.6 (2016): 1588-1591.

42. Gill P., et al. "Bombing alone: Tracing the motivations and antecedent behaviors of lone-actor terrorists". Journal of Forensic Sciences 59.2 (2013): 425-435.

43. Paulhus DL and Williams KM. "The Dark Triad of personality: Narcissism, Machiavellianism, and Psychopathy". Journal of Research in Personality 36 (2002): 556-563.

44. Johnson L., et al. "Subclinical sadism and the Dark Triad". Journal of Individual Differences (2019): 1-7.

45. Szabó E and Jones D. "Gender differences moderate Machiavellianism and impulsivity: Implications for Dark Triad research". Personality and Individual Differences 141 (2019): 160-165.

46. Jones D and Paulhus D. "Duplicity among the dark triad: Three faces of deceit". Journal of Personality and Social Psychology 113.2 (2017): 329-342.

47. Sandhya Nair. "Child Soldiers and International Criminal Law". Is the existing legal framework adequate to prohibit the use of children in conflict. Perth ILJ (2014): 40.

48. Child Soldiers International. Child soldier levels doubled since 2012 and girls' exploitation is rising Child Soldiers International (2019).

49. Özerdem A and Podder S. "Disarming youth combatants: Mitigating youth radicalization and violent extremism". Journal of Strategic Security 4.4 (2011): 63-80.

50. Encyclopedia Britannica. "Red Brigades | Italian militant organization". Encyclopedia Britannica (2019).

51. Collins Dictionary Online. Definition of 'Deradicalization' [Internet]. Collins Dictionary Online (2019).

52. Rabasa A., et al. Deradicalizing Islamist Extremists RAND-National Security Research Division (2010).

53. Hassan "ASRB Denmark's De-radicalisation programme for returning foreign terrorist fighters". Counter Terrorist Trends and Analyses 11.3 (2019):13-16.
54. Mahmood S. "Thematic challenges in terrorism: Foreign terrorist fighters, de-radicalisation and far-right groups". Counter Terrorist Trends and Analyses 11.5 (2019).

55. Silke A and Veldhuis T. "Countering violent extremism in prisons: A review of key recent research and critical research gaps". Perspectives on Terrorism 11.5 (2017): 2-11.

56. Department of Education. The Prevent duty departmental advice for schools and childcare providers (2019).

\section{Volume 2 Issue 12 December 2019}

(C) All rights are reserved by Basavaraja Papanna., et al. 